\title{
Use of Intelligent Agents in Collaborative M- Learning: Case of Facilitating Group Learner Interactions
}

\author{
Stephen T. Njenga \\ Murang'a University of Technology, School of Computing \& Information Technology, Kenya \\ Email: snjenga@mut.ac.ke \\ Robert O. Oboko and Elijah I. Omwenga \\ University of Nairobi, School of Computing \& Informatics, Kenya \\ Email: roboko@uonbi.ac.ke; eomwenga@uonbi.ac.ke \\ Elizaphan M. Maina \\ Kenyatta University, School of Engineering \& Technology, Kenya \\ Email: maina.elizaphan@ku.ac.ke
}

Received: 26 May 2017; Accepted: 08 August 2017; Published: 08 October 2017

\begin{abstract}
Intelligent agents have been used in collaborative learning. However, they are rarely used to facilitate group interactions in collaborative m-learning environments. In view of this, the paper discusses the use of intelligent agents in facilitating collaborative learning in mobile learning environments. The paper demonstrates how to design intelligent agents and integrate them in collaborative mobile learning environments to allow group learners to improve their levels of group knowledge construction. The design was implemented in a collaborative mobile learning system running on Modular Object-Oriented Dynamic Learning Environment (Moodle) platform. The application was used in some experiments to investigate the effects of those facilitated interactions on the level of group knowledge construction. The results showed improved levels of group knowledge construction in instances where the facilitations were enabled compared to where they were disabled. The paper concludes that the use of intelligent agents in facilitating learner group interactions in collaborative mobile learning environments improves the levels of group knowledge construction. For future work, the use of intelligent agents can be tested in other areas of group interactions to enhance group learning.
\end{abstract}

Index Terms-Intelligent agent, Collaborative mobile learning, Facilitated group participation, Regulated group cognitive conflicts, Moodle.

\section{INTRODUCTION}

Effective learning is attained when learners take an active role in their own learning and learning together as a group [1]. By working in groups students encourage, support, help and provide feedback to each other in order to improve their learning performance. Through collaborative learning, students articulate their own ideas, evaluate, question, sharpen, or build on the ideas of others, to deepen both their individual and collective conceptual understanding [2].

Student engagement in collaborative learning can be improved when they provide information, ask questions, and provide answers through elaborations and explanations. The verbalization of knowledge through justifying their actions to each other has a positive effect on learning [3]. Learners themselves understand the learning content better when they provide explanations to help their fellow students understand the material [4]. This way, they improve their comprehension of concepts leading to shared understanding from negotiated meaning [5]. Thus, students who do not provide explanations do not benefit from collaboration as much as the ones who provide [6]. Thus, it is a challenging task to facilitate an effective learning experience through quality student interactions [7]. With this in mind, the discussion platforms in Learning Management Systems do not automatically support knowledge construction [8].

The networked nature of mobile phones produces a good environment for collaboration in mobile learning. However, m-learning is still immature in areas of pedagogical considerations [9] since most mobile learning systems do not provide support for the collaborative learning processes [10]. With the presence of a variety of behavioral and interaction mechanisms to both promote and suppress learning in groups [11], proper design of interaction within the learning environment can significantly improve student achievement [12].

Thus, this paper aims to achieve two specific objectives: 
- To design and implement an architecture for facilitating collaboration in mobile learning using intelligent agents

- To investigate the effect of facilitated learner participation on the level of group knowledge construction in collaborative m-Learning group interaction processes.

- To investigate the effect of regulated group cognitive conflicts on the level of group knowledge construction in collaborative $\mathrm{m}$ Learning group interaction processes.

The rest of the paper is organized as follows: Section II discusses related work in collaborative m-learning and the use of intelligent agents in collaborative learning, Section III discusses the facilitations of the group interactions and the agent-based Architecture for mobile learning, Section IV explains the methodology used, Section $\mathrm{V}$ gives the results of the study, and Section VI contains the conclusion and further work.

\section{RELATED WORK}

Researchers have associated successful collaborative learning with two cornerstones, which are based on constructivism: they are (a) shared knowledge construction, and (b) productive collaborative interactions [13]. Learners engage in higher mental processes when creating knowledge through social negotiations and interactions [14]. During this engagement, students ask and respond to questions, reflect on contributions from their peers, show initiatives and become responsible for their own and other's learning [15].

Even though collaboration is beneficial for learning, successful collaboration is evasive and positive learning outcomes are not definite [16]. The collaborative learning environment should be one that enables students to be proactive and independent in their collaboration [17].

\section{A. Collaborative Knowledge Construction}

It is a requirement in collaborative learning that students become aware of the group processes and jointly construct knowledge in order to benefit from the collaboration [6]. As a social interaction, collaborative learning involves group members who acquire and share their learning experience or knowledge [18]. During knowledge construction, the learners collectively enquire by participating in discussions and interactive questioning which leads to improvement of ideas [19]. Thus, knowledge construction itself is a product of collaborative learning [20]. This paper considers two important requirements for effective group knowledge construction: group participation and group cognitive conflicts.

Engaging (participating) in a dialogue, especially an argument is vital to collaborative learning from a constructivism view [21]. Engagement allows for structuring and restructuring of ideas within a discussion group, with multiple views coming from individuals when negotiating meaning in the process of learning [22].
However, participation in a group discussion has its own challenges. Some group members may decide not to contribute while others may dominate the group. This could lead to reduced trust and cooperation within the group [23]. An effective collaborative task is one that enables all participants to express themselves and make significant contributions [24]. In the view of participation, successful collaboration acknowledges that everyone has ideas to contribute in the collaborative learning [25]. Encouraging group members to participate ensures that almost all of them understand the topic or problem being solved.

A cognitive conflict occurs when a learner becomes aware of a discrepancy between one's existing cognitive framework and new information or experiences from other sources [5]. The presence of cognitive conflicts is noted when peers argue amongst themselves, clarify and evaluate each other's ideas leading to cognitive restructuring [26]. Cognitive conflicts have the potential to stimulate the learning process [27] and are vital in an individual's conceptual change during learning [28]. Cognitive conflicts allow a learner to identify, challenge and reconstruct any likely misconceptions. The presence of group cognitive conflicts enable ideas and assumptions from all group members, which might otherwise lead to incomplete analysis and improper decisions, to be uncovered [29]. The disagreements in terms of knowledge cognitive conflicts 'force' participants to provide explanations, give reasons, and justify their views [5]. Thus, cognitive conflicts should be encouraged so long as they don't degenerate into potential relational disagreements [29].

\section{B. Intelligent Agents in Collaborative Learning}

An agent is computer software which works autonomously, is interactive in nature and communicates by sending and receiving messages within some environment. Intelligent agents have been used in collaborative learning by incorporating learning theories [30] and can provide control over interaction and assessment for group members [31]. Intelligent agents are preferred due to their high degree of selfdetermination capabilities and their capability to decide for themselves when, where, and under what condition to perform their actions [32].

One type of intelligent agents called Intelligent Pedagogical Agents (IPA) provide pedagogical guidance, tutorials, ability to find learning resources, tracking learners' progress, aid collaborative and communicating learning functions, give guidance, and motivate learners [33]. There are two subcategories of IPAs: conversational agents and teachable agents. Conversational agents facilitate conversations amongst learners while teachable agents learn from the students in order to perform some specific tasks later [34]. Conversational agents perform a number of tasks including enhancing menus and interactive simulations and providing a wide range of conversational contexts and collaborative interactions [35]. The use of conversational agents provides dynamic support for collaborative learning leading to improved 
learning outcomes [36]. Agents are favorable in collaborative learning since they adapt to the learning experience in order to meet the learner's requirements or meet the changes in the learning environment [37].

\section{FACILITATING GROUP INTERACTIONS IN COLLABORATIVE LEARNING}

The difficulties in collaboration are as a result of poorly designed learning activities and problems with communication of activities within the collaboration environment. Students require guidance on how to interact during collaborative learning [38]. The facilitation of collaborative interactions leads to better and effective collaborative learning [39]. There is need to restructure collaborative learning in order to realize promotive behaviors which are typically not present (or are erratically present), and eliminate the suppressive behaviors which are very common in group learning [6].

Group facilitation is influential in shaping a group discussion and consequently affects the students' group knowledge construction [40]. This raises the need to facilitate the group learning experience through quality learner interaction and engagement [7]. The methods of supporting collaborative learning can be summarized into three approaches: (1) identifying the collaborative joint work activities and presenting them to participants so that they can understand their collaborative acts; (2) monitoring and modeling all interactions among the learners and noting differences between the ideal state and the current state; and (3) analyzing the state of collaborative learning and providing advice for effective collaboration [41].

In their study, [42] identified some important facilitation techniques used by instructors to enhance knowledge construction including (i) identifying areas of agreement/disagreement, (ii) seeking to reach consensus/understanding, (iii) encouraging learners to participate, (iv) acknowledging, or reinforcing student contributions, (v) focusing the discussion on specific issues, (vi) confirming understanding through assessment and explanatory feedback, and (vi) diagnosing misconceptions. This study concentrates on most of the approaches identified above to facilitate group participation and regulate group cognitive conflicts.

\section{A. Facilitating Group Learner Participation}

The success of collaborative learning largely depends on student participation in a group learning activity [43]. There is need to actively promote participation in collaborative learning [44] using a design to encourage students to participate in shared knowledge-construction processes [45]. This paper concentrates two types of facilitations to promote group participation: turn taking and informative feedback.

Equal opportunity to participle is a key factor in determining group's ability to solve problems, create ideas and make decisions [46]. Turn taking is a group facilitation which uses turn allocation techniques for selecting the next contributor to the group task [47]. Turn taking uses a round robin strategy where every group member is provided with an opportunity to make a contribution about a group issue [23]. A member without any contribution to make can 'pass' the opportunity to the next member. The group members can use their opportunity to question, clarify and reword their peers' contributions to confirm their own understanding of the team's interpretation of the problem and the proposed solutions. Thus, turn taking ensures that there is no group domination because everyone gets an equal chance to contribute.

Feedback is a type of help offered by group members to each other in collaborative learning. Informative feedback is a suitable way to encourage quality participation and interaction to facilitate knowledge creation [48]. Timely feedback is critical for facilitating a comfortable learning environment [49] and assists participants to improve on their contributions [50]. According to the constructivist theory, the instructor's intention is to intervene during the learning process and not to take charge of the process; so should feedback be [51]. The aim of providing feedback is to encourage students by asking them questions and challenging their ideas during the group discussions [52]. Other than motivating the students to participate, feedback can also provide information about the student participation in a collaborative environment [53]. The instructors can use the measured level of participation to provide appropriate feedback [43]. For example, low engagement can be improved through encouraged participation. Also, any imbalance in student participation can be easily noted by monitoring the students' engagement in group activities. This not only facilitates for intervention by the instructor, but also allows for the students to gauge themselves and improve their engagement [6].

\section{B. Regulating Group Cognitive Conflicts}

It is important to resolve group conflicts which arise during group knowledge construction [27]. The way those conflicts are dealt with and the ability to resolve them affects group learning [54] by determining how well the group members create a shared understanding of the problem they are solving jointly. However, not much research has been done on how students deal with group conflicts on knowledge which arise during collaboration, and how they can be facilitated [27]. Differences exist on how low and high achieving students deal with cognitive conflicts. High achieving students are comfortable with cognitive conflicts, while low achieving students try to avoid them [55]. This paper uses two approaches for regulating group cognitive conflicts, namely role playing and guided negotiation.

During collaborative learning, roles often arise which determine the level of interaction and the learning outcomes. The interaction which is built during collaboration through questions, critique, and requests for clarification or justification often influence how the roles emerge [56]. Role-playing increases the interactions during knowledge construction in collaborative discussions [57]. The multiple functions which a member 
can perform are ignored when a member is confined to a single role [58]. Group roles which arise during collaborative learning make the group members to assume responsibilities on themselves or others [59]. Assigning new roles make participants to look at the group problem from a different perspective leading to improved students' engagement with each other towards successful collaborative task [60].

According to [61], group knowledge negotiation is crucial in collaborative learning and especially in collaborative knowledge building. Group negotiation involves multiple alternatives and starting positions provided by group members. Members discuss alternatives, question and challenge positions of others which consequently alter their understanding of knowledge through consensus. Thus, negotiation is not just a reconciliation of multiple opinions but a process of collaborative construction of new knowledge based on interaction and discourse, rather than the selection of an opinion among alternatives. Thus, through negotiation the group members adopt new shared goals leading to broader shared understanding [62]. The use of interaction rules is could be an easy way of regulating the group negotiation (e.g. each member can come up with three ideas) [63].

\section{Collaborative M-Learning Agent Based Architecture (CMABA)}

The four facilitations discussed in the section above were used in developing the agent-based architecture discussed here. There is no standardization concerning the agent components of a system or their roles [64]. This agent architecture brings together a number of software modules implemented using intelligent agents. These agents in software modules choose actions and react to change the environment they operate in.

This architecture uses automatic analysis of collaboration as the design approach and detects when an agent should intervene. It uses intelligent pedagogical agents (IPAs) which aim to provide automated and intelligent pedagogical support while improving engagement throughout collaboration. Specifically, the agents collect information, analyze it and generate alternatives that allow the user to focus on the effort to solve the group problem. This collaborative m-learning environment consists of four intelligent agents which deal with different facilitations for interaction during collaborative learning.

Each intelligent agent implements one of the four facilitations discussed in Section III above. As shown in Fig. 1, the two agents used for facilitating group participation are turn-taking agent and informative feedback agent, while the two agents used for regulating group cognitive conflicts are role playing agent and guided negotiation agent. The architecture was developed to run on a Moodle Learning management system. This architecture (CMABA) was developed due to lack of a sound framework and methodological approach of using agents in collaborative learning [32].
The architecture has four layers: User Layer, Mobile Platform Layer, System Layer and Database Layer. The User Layer is used for communication between the mobile application users and the system through online discussion forums. The Mobile Platform Layer is made of the mobile phone interfaces which allow the students to interact and access the system using their mobile phones. It caters for the support of different types of phones available to the students through a mobile network. The System Layer is the core of this architecture and consists of the four Intelligent Agents and runs on top of the Moodle Learning Management system platform. The implementation of the intelligent agents is done in this layer. The Database Layer allows for the storage and access of application's data, such as the number and names discussion groups, discussion forum messages posted by students, etc.

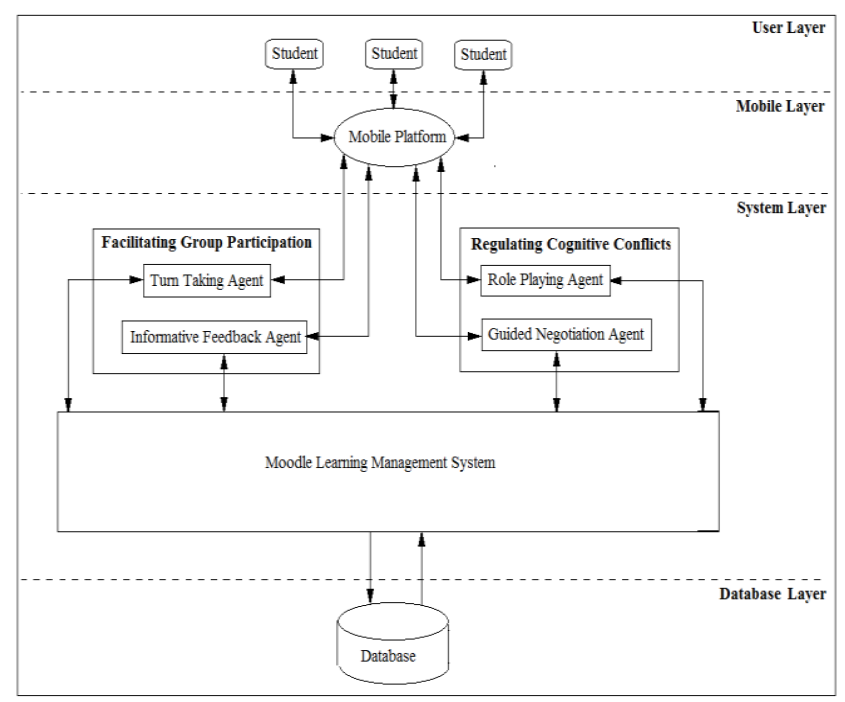

Fig.1. Collaborative M-learning Agent-based Architecture (CMABA)

The turn taking agent regulates the members' contributions in a discussion by allocating each member a time slot in a round robin approach. The implication is that a member cannot contribute twice before other members from the same group contribute to the discussion. The algorithm used by this agent is shown in Fig. 2.

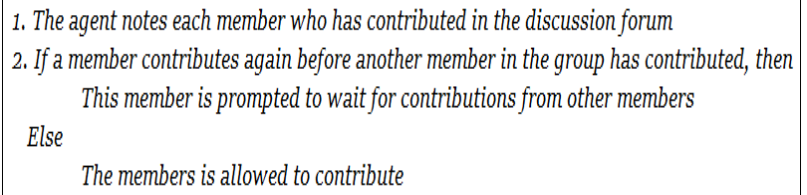

Fig.2. Algorithm for Turn Taking Agent

The informative feedback agent monitors the participation of each member in the group discussion. The agent calculates the participation statistics based on percentage contribution by each member of the group. The passive (dormant) members are prompted to contribute through reminders and asking their opinions in the course of the discussion. The dominant members are 
requested to provide chances to other members. The algorithm for Informative Feedback agent is shown in Fig. 3.

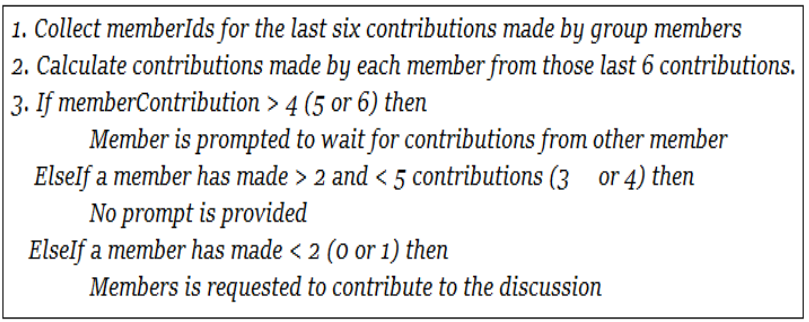

Fig.3. Algorithm for Informative Feedback agent

The Role Playing agent encourages a member to choose a role by providing the possible roles as a way of regulating the group cognitive conflict. Different roles are provided with different set of tasks which determine the way a discussion takes place. The agent also dynamically gives the current role played by each group member to the others. For example, a member could initiate a discussion (starter role) and later support a member's contribution (supporter role) as the discussion continues. The algorithm for the role playing agent is shown in Fig. 4.

1. Identify the current role played by each group members from the contributions

2. Display the different roles played by the all group members in the discussion forum and their specific duties

3. Suggests possible roles and allows for role selection during the discussion.

4. Allow and facilitate swapping of roles by the participants themselves every time they participate in the discussion.

5. If member selects different role

Display update to show current role and associated responsibilities

Fig.4. Algorithm for Role Playing agent

The Guided Negotiation agent assists the students by providing then with sentence openers to allow them to choose the type of contribution they want to make. The sentence openers used are Propose, Counter-Propose, Agree/Disagree, Question, Answer and Provide Information. The student selects the sentence opener and then makes the contribution to the discussion based on that selection. This agent also provides the students with an option to elaborate or explain their contributions. The algorithm for this agent is displayed in Fig. 5.

1. The agent provides a group member with a set of sentence guides and elaboration options to choose from

2. The group member chooses the sentence guide matching the type of contribution to make

3. The agent checks whether the contribution made by member matches the sentence guide

4. If match then Else Contribution accepted

Member given another chance to contribute

5. If the member wishes to elaborate or explain the contribution Member selects the option to elaborate/explanation and types an elaboration/explanation

Fig. 5. Algorithm for Guided Negotiation agent

\section{Validating and Testing the Mobile Application}

The architecture was used in developing software plugin for Moodle Learning Management System. A database was used for storage of the data for the application. The application was given to students to participate in testing and validating it.

The students were taught in a unit called Object Oriented Programming. The lecture notes were uploaded in the system and the students downloaded the notes using their mobile phones. The students were later randomly assigned into discussion groups of three members each. The discussion groups were then randomly assigned to four experimental groups and one control group to participate in testing the workability of the application. The experimental groups were based on the four types of facilitations provided in the application, that is, turn taking group, informative feedback group, role playing group and guided negotiation group. All the groups were given a similar group discussion problem to solve.

The students participated in the group discussions and continuously gave their feedback to the facilitator on issued concerning problems and challenges they faced when using the mobile application. The results of the prestudy were used in improving the design of the software, and consequently used in improving the final application. The data collected from the application was concerned with the problems encountered by the students during the group discussions. The students were provided with a facility to send feedback to the application developers through short messages, email and text within the discussion forum. The problems encountered by the students were grouped into two categories namely functional and operational problems.

The functional problems were as a result of the application not performing as expected based on the functional requirements. For example, the non-visibility of the posted messages on the discussion platform, lack of turns in turn taking group, improper regulation of the guided negotiation group etc. The feedback from the functional problems encountered was used to improve the functional requirements and the overall design of the application.

Operational problems resulted from the students not being able to use the application as expected. For example, some participants (especially those in the Role playing and Guided Negotiation groups) did not fully understand how to access and participate in the group discussions. The messages posted in the group discussions also gave important information about group participation and chronological order of posted messages. This feedback prompted some changes to be made in the algorithms affected and enhance the application usage by providing instructions to the students.

The architecture was improved and enhanced as appropriate and used in developing the final mobile application. The mobile application was later given to the students to take part in two experimental studies aimed at investigating the effect of facilitated group interactions on the group knowledge construction. 


\section{METHOLOGY}

Two experiments were conducted in this study. The first experiment investigated the effect of facilitated group learner participation on the level of group knowledge construction and the second experiment investigated the effect of regulated group cognitive conflicts on the level of group knowledge construction.

\section{A. Experiment 1 - Use of facilitated Group Participation on Group Knowledge Construction}

This experimental study was done using students from Kenya who undertook a unit called "Data Structures and Algorithms" in a 14-week semester. The study used a post-test control group design with random assignment of the discussion groups. According to [65], students in small groups (two to four members) get satisfied with group learning and get more benefits with online discussions.

All the participants were registered to the mobile application in order to access the lecture notes after they were given an explanation on how to participate in the experiment. They were given the assurance that their participation towards the experiment would not be disclosed and neither used in assessing them for the semester score.

The students participated in an online group discussion in the 8th week of the semester. A total of 90 students formed 30 discussion groups of three members each through self-selection based on their working familiarity with each other based on previous class discussions. The 30 discussion groups were randomly assigned to two experimental groups (informative feedback group and turn taking group) and one control group. Each treatment group was assigned 10 discussion groups. The experimental design used (see Table 1) was adopted from [66].

Table 1. Experimental Design showing groups, treatments and observations

\begin{tabular}{|l|l|l|}
\hline Group & Treatment & Posttest \\
\hline Experimental Group 1 & $\mathrm{X}_{1}-$ Use of turn taking & $\mathrm{O}_{1}$ \\
\hline Experimental Group 2 & $\begin{array}{l}\mathrm{X}_{2}-\text { Use of informative } \\
\text { feedback }\end{array}$ & $\mathrm{O}_{2}$ \\
\hline Control Group & & $\mathrm{O}_{3}$ \\
\hline
\end{tabular}

The difference in the treatment groups was due to the type of facilitated participation technique used by the students in each group during collaborative learning. Each of the facilitation was enabled or disabled depending on the specific needs for each treatment group.

Treatment 1: The members of this group used informative feedback for the facilitated group participation.

Treatment 2: The members of this group used turn taking as the technique for facilitating group participation.

Treatment 3: This was the control group where the participants were not required to use either the turn taking facilitation or the informative feedback support. Both the informative feedback and turn taking facilitations were disabled.

Each discussion group was provided with an illstructured group problem in the online group discussion posted within the collaborative m-learning application. All the contributions made by each group when solving the group problem were stored in the application's server. All the group discussions took place simultaneously for a period of one week. However, no discussion group could view the discussion contents of the other groups.

\section{B. Experiment 2 - Use of regulated Group Cognitive Conflicts on Group Knowledge Construction}

This experiment was conducted using students from a local university in Kenya. The students were taught a subject 'Design and Analysis of Algorithms' in a 14week semester. A total of 30 participants took part in the experimental study. After being registered to use the application for accessing their lecture notes, the students took part in three online discussions from the $6^{\text {th }}$ week. The participants were placed into discussion groups of three members each through self-selection. The discussion groups were randomly assigned to the two experimental groups and one control group in the first online discussion. In the second online discussion, each discussion group was given a different treatment condition from the first one. Again, in the third online discussion, each group participated in a different treatment condition from the first and the second discussion. The experiment used multiple treatment design. The treatment conditions are as follows:

Treatment 1: The members of this group used role playing as the technique for regulating group cognitive conflicts.

Treatment 2: The members of this group used guided negotiation for regulating the cognitive conflicts.

Treatment 3: This was the control group. The participants in this group used neither role playing nor guided negotiation.

Each discussion group participated in three discussions by solving three ill-structured problems for each of the three treatment conditions. One-week duration was observed between each online discussion. The posted messages were saved in the application's server.

\section{RESULTS}

These results are presented according to each experiment.

\section{A. Results for Experiment 1}

A total of 364 messages were posted by 90 students who participated in the online group discussion. To facilitate analysis, the posted text messages were exported to Excel. The data was then sorted using groupID (identifier for discussion group) and then by Time Created (time the message was posted). The posted messages were categorized into different knowledge level codes by two independent coders using the Content Analysis Tool adopted from [67]. According to this tool, 
each contribution is ranked depending on its contribution to the discussion using an evaluation criterion. The interrater agreement's Kappa value for the posted messages was 0.723 . A value between 0.61 and 0.80 is a substantial agreement while one between 0.81 and 1.00 is almost perfect agreement [68]. A third rater was involved in categorizing the messages where the two raters did not agree. A consensus was reached by the three coders in cases where two of the three coders did not agree.

The mean levels of knowledge construction for each discussion group were calculated using the assigned values by the raters. Those mean levels of knowledge construction were used for further analysis in this experiment.

According to Table 2 the control group registered a lower mean value (6.91) than that of both the informative feedback group (8.36) and turn taking group (8.56). The level of knowledge construction for the control group ranges from 5.24 to 8.30 compared to the ones for informative feedback group (7.16 to 10.00) and turn taking group (7.88 to 9.83 ).

Table 2. Means and variances for facilitated group participation

\begin{tabular}{|c|c|c|c|c|c|c|c|c|}
\hline & $\mathrm{N}$ & Mean & $\begin{array}{l}\text { Std. } \\
\text { Deviation }\end{array}$ & $\begin{array}{l}\text { Std. } \\
\text { Error }\end{array}$ & $\begin{array}{l}95 \% \text { C } \\
\text { Interva } \\
\text { Mean } \\
\text { Lower } \\
\text { Bound } \\
\end{array}$ & $\begin{array}{l}\text { Confidence } \\
\text { al for } \\
\begin{array}{l}\text { Upper } \\
\text { Bound }\end{array}\end{array}$ & Minimum & Maximum \\
\hline 1 & 10 & 6.91 & 0.94 & 0.30 & 6.23 & 7.58 & 5.24 & 8.30 \\
\hline 2 & 10 & 8.36 & 1.00 & 0.32 & 7.65 & 9.07 & 7.16 & 10.00 \\
\hline 3 & 10 & 8.56 & 0.67 & 0.21 & 8.08 & 9.03 & 7.88 & 9.83 \\
\hline Total & 30 & 7.94 & 1.13 & 0.20 & 7.52 & 8.36 & 5.24 & 10.00 \\
\hline
\end{tabular}

A significant difference was noted in the level of knowledge construction between the control group (1) and the informative feedback group (2) $(p=0.003)$ and between the control group and the turn taking group ( $p=$ 0.001) (see Table 3). The level of knowledge construction was statistically significantly higher when using the facilitations for informative feedback (at a level of $8.36 \pm 0.32, p=0.003)$ and turn taking $(8.56 \pm 0.21)$ compared to the control group (neither turn taking nor informative feedback) (at a level of $6.90 \pm 0.30$ ).

Table 3. Multiple Comparisons for the treatment groups

\begin{tabular}{|c|c|c|c|c|c|c|}
\hline \multirow{3}{*}{$\begin{array}{l}\text { (I) } \\
\text { Facilitation }\end{array}$} & \multirow{3}{*}{$\begin{array}{l}(\mathrm{J}) \\
\text { Facilitation }\end{array}$} & \multirow{3}{*}{$\begin{array}{l}\text { Mean } \\
\text { Difference } \\
(\mathrm{I}-\mathrm{J})\end{array}$} & \multirow[b]{3}{*}{ Std. Error } & \multirow[b]{3}{*}{ Sig. } & \multicolumn{2}{|c|}{$\begin{array}{l}95 \% \text { Confidence } \\
\text { Interval }\end{array}$} \\
\hline & & & & & Lower & Upper \\
\hline & & & & & Bound & Bound \\
\hline \multirow[t]{2}{*}{1} & 2 & $-1.45^{*}$ & 0.39 & 0.003 & -2.43 & -0.48 \\
\hline & 3 & $-1.65^{*}$ & 0.39 & 0.001 & -2.63 & -0.67 \\
\hline \multirow[t]{2}{*}{2} & 1 & $1.45^{*}$ & 0.39 & 0.003 & 0.48 & 2.43 \\
\hline & 3 & -0.20 & 0.39 & 0.871 & -1.17 & 0.78 \\
\hline \multirow[t]{2}{*}{3} & 1 & $1.65 *$ & 0.39 & 0.001 & 0.67 & 2.63 \\
\hline & 2 & 0.20 & 0.39 & 0.871 & -0.78 & 1.17 \\
\hline
\end{tabular}

\section{B. Results for Experiment 2}

A total of 324 messages were posted by 30 participants who participated in all the three treatment conditions. After categorizing the messages into different knowledge level codes by two independent coders using the Content
Analysis Tool [67], an inter-rater agreement of 0.726 was achieved. A consensus was applied where two of the three coders did not agree. The average level of group knowledge construction was calculated for each group.

The mean group level of knowledge construction for the guided negotiation group (2) and role playing group (3) was higher than the one for the control group (1). Table 4 shows that the mean for the control group is 5.0001 being lower than those for both the Guided Negotiation (7.54) and Role Playing (6.72).

Table 4. Descriptive Statistics

\begin{tabular}{|l|l|l|l|}
\hline & Mean & Std. Deviation & N \\
\hline Control & 5.00 & 2.64347 & 10 \\
\hline Guided Negotiation & 7.54 & 2.28883 & 10 \\
\hline Role Playing & 6.72 & 1.70702 & 10 \\
\hline
\end{tabular}

A repeated measures ANOVA was done on the messages posted during the discussion. Mauchly's test was done to check the sphericity condition. As shown in Table 5, the variances of the 'between levels of knowledge construction' were not significant (significance value is 0.764 which is above 0.05 ).

Table 5. Maulchy's Test of Sphericity

\begin{tabular}{|c|c|c|c|c|c|c|c|}
\hline \multirow{2}{*}{$\begin{array}{l}\text { Within } \\
\text { Subjects } \\
\text { Effect }\end{array}$} & \multirow{2}{*}{$\begin{array}{l}\text { Mauchly's } \\
\text { W }\end{array}$} & \multirow{2}{*}{\begin{tabular}{|l|} 
Approx. \\
Chi- \\
Square
\end{tabular}} & \multirow{2}{*}{ df } & \multirow[t]{2}{*}{ Sig. } & \multicolumn{3}{|l|}{ Epsilona } \\
\hline & & & & & $\begin{array}{l}\text { Greenhouse- } \\
\text { Geisser }\end{array}$ & $\begin{array}{l}\text { Huynh- } \\
\text { Feldt }\end{array}$ & $\begin{array}{l}\text { Lower- } \\
\text { bound }\end{array}$ \\
\hline $\begin{array}{l}\text { Facilitatio } \\
\mathrm{n}\end{array}$ & .935 & .539 & 2 & .764 & .939 & 1.000 & .500 \\
\hline
\end{tabular}

The lack of significant differences in Table 5 indicates that the assumption of sphericity was not violated. With sphericity not violated, Table 6 was used to further indicate a significant difference in the level of knowledge construction in the three treatment groups $(\mathrm{F}=13.65, \mathrm{p}<$ $0.01)$.

Table 6. Tests of Within-Subjects Effects

\begin{tabular}{|c|c|c|c|c|c|c|}
\hline \multicolumn{2}{|l|}{ Source } & \begin{tabular}{|l|} 
Type \\
III Sum \\
of \\
Squares
\end{tabular} & df & $\begin{array}{l}\text { Mean } \\
\text { Square }\end{array}$ & $\mathrm{F}$ & Sig. \\
\hline \multirow[t]{4}{*}{ Facilitation } & $\begin{array}{l}\text { Sphericity } \\
\text { Assumed }\end{array}$ & 63.13 & 2 & 31.57 & 13.65 & .000 \\
\hline & $\begin{array}{l}\text { Greenhouse- } \\
\text { Geisser }\end{array}$ & 63.13 & 1.88 & 33.62 & 13.65 & .000 \\
\hline & Huynh-Feldt & 63.13 & 2.00 & 31.57 & 13.65 & .000 \\
\hline & Lower-bound & 63.13 & 1.00 & 63.13 & 13.65 & .005 \\
\hline \multirow[t]{4}{*}{ Error(Facilitation } & $\begin{array}{l}\text { Sphericity } \\
\text { Assumed }\end{array}$ & 41.62 & 18 & 2.31 & & \\
\hline & $\begin{array}{l}\text { Greenhouse- } \\
\text { Geisser }\end{array}$ & 41.62 & 16.90 & 2.46 & & \\
\hline & Huynh-Feldt & 41.62 & 18.00 & 2.31 & & \\
\hline & Lower-bound & 41.62 & 9.00 & 4.62 & & \\
\hline
\end{tabular}

From Table 7, the estimated marginal mean for the control group is $4.59 \pm 0.48$, the one for Guided Negotiation is $7.95 \pm 0.56$ and the mean for Role Playing is $7.27 \pm 0.42$. 
Table 7. Estimated marginal means

\begin{tabular}{|l|l|l|l|l|}
\hline \multirow{2}{*}{ Facilitation } & Mean & Std. Error & \multicolumn{2}{|l|}{$95 \%$ Confidence Interval } \\
\cline { 4 - 5 } & & & Lower Bound & Upper Bound \\
\hline 1 & 4.59 & 0.48 & 3.51 & 5.66 \\
\hline 2 & 7.95 & 0.56 & 6.70 & 9.219 \\
\hline 3 & 7.27 & 0.42 & 6.30 & 8.22 \\
\hline
\end{tabular}

\section{CONCLUSION AND FUTURE WORK}

The analysis of the relationships between the independent variable for facilitating group interactions (with two levels - facilitated group participation and regulated group cognitive conflicts) and the dependent variable knowledge construction showed evidence of what might make mobile learning management systems to be more helpful to the group learners.

Based on experiment 1 , it can be concluded that facilitated group participation improves the level of group knowledge construction. The use of both turn taking and informative feedback facilities resulted to improved levels of knowledge construction. The successful implementation of facilitations for group participation using intelligent agents in Moodle Learning Management systems suggest that collaborative mobile learning can be improved in terms of group participation and consequently improving group knowledge construction.

From the results of experiment 2, it can be concluded that the use of both role playing and guided negotiation improves the level of group knowledge construction. The intelligent agents seem to be effective in collection and analysis of group interactions to dynamically regulate the group discussions. Table 7 gives a clear indication that the facilitations for regulating cognitive conflicts (Guided Negotiation and Role Playing) improved the level of knowledge construction in the discussion groups.

The Architecture works well for collaborative mobile learning based on Moodle Learning Management System. While there is room for improving this architecture, we will also consider implementing it on other mobile learning platforms. Also the architecture may be modified to capture the aspect of agents working together by sharing their information to improve the learning effect on collaborative platforms.

\section{ACKNOWLEDGMENT}

The authors wish to thank the National Commission for Science and Technology Innovations (NACOSTI) Kenya. This work was supported in part by a research grant from NACOSTI.

\section{REFERENCES}

[1] Griffin, P., Care, E. \& McGaw, B. (2012). The changing role of education and schools. In P. Griffin, B. McGaw \& E. Care (Eds.), Assessment and teaching 21st century skills, 1-15.

[2] Fischer, F., Kollar, I., Stegmann, K., \& Wecker, C. (2013). Toward a script theory of guidance in computer-supported collaborative learning. Educational Psychologist, 48(1), 56-66.
[3] Jaimini, N. (2014). Group Dynamics in Collaborative Learning: Contextual Issues and Considerations. Impact: International Journal of Research in Humanities, Arts and Literature (IMPACT: IJRHAL) ISSN (E): 2321-8878; ISSN (P): 2347-4564 Vol. 2, Issue 2, Feb 2014, 83-88.

[4] Howe, C., Tolmie, A., Thurston, A., Topping, K., Christie, D., Livingston, K., Jessiman, E. \& Donaldson, C. (2007). Group work in elementary science: Towards organizational principles for supporting pupil learning. Learning and Instruction, 17,549-563.

[5] Lai, E. R. (2011). Collaboration: A Literature Review. Pearson Research Report, 2.

[6] McLaren, B. (2014). What Happens When We Learn Together. A Research-Based Whitepaper on the Power of Collaborative Learning.

[7] Song, L. \& McNary, S. (2011). Understanding students' online interaction: Analysis of discussion board postings. Journal of Interactive Online Learning, 10(1), 1-14.

[8] Zingaro, D. (2012). Student moderators in asynchronous online discussion: A question of questions. MERLOT Journal of Online Learning and Teaching, 8(3), 159-173

[9] Park, Y. (2011). A Pedagogical Framework for Mobile Learning: Categorizing Educational Applications of Mobile Technologies Into Four Types. The International Review of Research in Open and Distance Learning, 12 (2).

[10] Wu, W.-H., Wu, Y.-C., Chen, C.-Y., Kao, H.-Y., Lin, C.-H., \& Huang, S.-H. (2012). Review of trends from mobile learning studies: A meta-analysis. Computers \& Education, 59(2), 817-827.

[11] Webb, N. M. (2013). "Information processing approaches to collaborative learning." In Hmelo-Silver, C.E., Chinn, C.A., Chan, C.K.K., and O'Donnell. A. (Eds.), The International Handbook of Collaborative Learning. Routledge: New York and London.

[12] Mahle, M. (2011). Effects of interactivity on student achievement and motivation in distance education. Quarterly Review of Distance Education, 12(3), 207-215.

[13] Järvelä S \& Hadwin A (2013) New Frontiers: Regulating Learning in CSCL. Educational Psychologist 48(1): 25-39.

[14] Laru J. (2012). Scaffolding learning activities with collaborative scripts and mobile devices (Doctoral dissertation, University of Oulu, Finland).

[15] Khoshneshin, Z. (2011). Collaborative critical thinking in online environment. Procedia -Social and Behavioral Sciences, 30, 18811887.http://dx.doi.org/10.1016/j.sbspro.2011.10.366

[16] Näykki, P. (2014). Affective and Effective Collaborative Learning. Process-Oriented Design Studies in a Teacher Education Context. Unpublished PhD Thesis, University of Oulu, Finland.

[17] Chan, C. K. K. \& Chan, Y. Y. (2011). Students' views of collaboration and online participation in Knowledge Forum. Computers \& Education, 57(1), 1445-1457.

[18] Zhu, C. (2012). Student Satisfaction, Performance, and Knowledge Construction in Online Collaborative Learning. Educational Technology \& Society, 15 (1), $127-136$.

[19] Zufferey, J.D., Bodemer, D., Buder, J. \& Hesse, F.W. (2010). Partner knowledge awareness in knowledge communication: Learning by adapting to the partner. The Journal of Experimental Education, vol. 79, no. 1, pp. 102-125.

[20] Shukor, N. A, Tasir, Z., Van der Meijden, H., \& Harun, J. (2014). Exploring Students' Knowledge Construction Strategies in Computer-Supported Collaborative Learning 
Discussions Using Sequential Analysis. Educational Technology \& Society, 17 (4), 216-228.

[21] Pritchard A and Woollard J (2010) Psychology for the Classroom: Constructivism and Social Learning. London and New York: Routledge.

[22] Bhattacharjee, J. (2015). Constructivist Approach to Learning - An Effective Approach of Teaching Learning. International Research Journal of Interdisciplinary \& Multidisciplinary Studies (IRJIMS). A Peer-Reviewed Monthly Research Journal ISSN: 2394-7969 (Online), ISSN: 2394-7950 (Print). Volume-I, Issue VI, July 2015, Page No. 65-74

[23] Terry, B. D. (2013). Working in Groups: Facilitating Positive Group Interactions.

[24] Rimor, R., Rosen, Y. and Naser. K. (2010). Complexity of Social Interactions in Collaborative Learning: The Case of Online Database Environment. Interdisciplinary Journal of E-Learning and Learning Objects. Volume 6, 2010. IJELLO special series of Chais Conference 2010 best papers.

[25] CORP/U (2013). Elements of Successful Collaboration: An Overview

[26] Snapwiz (2012). Improving Student Engagement by Integrating Adaptive and Collaborative Learning Technologies.

[27] Aarnio, M. (2015). Collaborative Knowledge Construction in the Context of Problem-Based Learning. Exploring learning from conflicting ideas and knowledge. $\mathrm{PhD}$ Thesis, University of Helsinki, Finland.

[28] Bao, L., Kim, Y., Raplinger, A., Han, J., \& Koenig, K. (2013). Affective Factors in STEM Learning and Scientific Inquiry: Assessment of Cognitive Conflict and Anxiety. Special Issue of Research on Education Assessment and Learning.

[29] Gutbezahl, C.D. (2010). Cognitive Conflict. The Cure for Anger in Hospitals. Managing Conflict to Help Create Better American Hospitals.

[30] Miao, C., Yu, H., Shen, Z. \& Tao, X. (2010). Agents for collaborative learning in Virtual Worlds. (Workshop on Opportunities for intelligent and adaptive behavior in collaborative learning system Supplementary Proceedings of the Tenth International Conference on Intelligent Tutoring Systems Pittsburgh, PA, USA).

[31] Looi, C. -K. (2014/15). How Collaborative Problem Solving might be assessed internationally at scale?

[32] Adla, A., Nachet, B. \& Ould-Mahraz, A. (2012). MultiAgents Model for Web-based Collaborative Decision Support Systems. $294-299$.

[33] Soliman, M. \& Guetl, C. (2010a). Review and Perspectives on Intelligent Multi-agent Systems' Support for Group Learning. World Conference on Educational Multimedia, Hypermedia \& Telecommunications EDMEDIA 2010, June 2010, Toronto, Canada.

[34] Veletsianos, G. \& Russell, G.S. (2013). Pedagogical Agents. J.M. Spector et al. (eds.), Handbook of Research on Educational Communications and Technology.

[35] OECD (2013). PISA 2015 Draft collaborative Problem Solving Framework. Paris, France: OECD Publishing. Retrieved from http://www.oecd.org/pisa/pisaproducts/pisa2015draftfram eworks.htm

[36] Kumar, R., \& Rosé, C.P. (2010), Conversational Tutors with Rich Interactive Behaviors that support Collaborative Learning (Workshop on Opportunities for intelligent and adaptive behavior in collaborative learning systems Supplementary Proceedings of the Tenth International
Conference on Intelligent Tutoring Systems Pittsburgh, PA, USA.)

[37] Henry, L. and Sankaranarayanan, S. (2010). Intelligent Agent based Mobile Learning System. International Journal of Computer Information Systems and Industrial Management Applications (IJCISIM). ISSN: 2150-7988 Vol.2 (2010), pp.306-319.

[38] Ruiz-Primo, M.A., Briggs, D., Iverson, H., Talbot, R., and Shepard, L.A. (2011). Impact of Undergraduate Science Course Innovations on Learning.

[39] Kim, M. K., Kim, S. M., Khera, O. \& Getman, J. (2014). The experience of three flipped classrooms in an urban university: An exploration of design principles. Internet and Higher Education, 22, 37 - 50.

[40] Hew, K. F. and Cheung, W. S. (2011). Higher-level knowledge construction in asynchronous online discussions: an analysis of group size, duration of online discussion, and student facilitation techniques. Instructional Science, Vol. 39, No. 3 (May 2011), pp. 303319.

[41] Soller, A., Jermann, P., Muhlenbrock, M. \& Martinez, A. (2004). Designing computational models of collaborative learning interaction. Proc. ITS 2004 Workshop, 5-12

[42] Lu, L.L. \& Jeng, I., (2006). Knowledge construction in inservice teacher online discourse: Impacts of instructor roles and facilitative strategies. Journal of Research on Technology in Education 39(2), 183-202.

[43] Liu, M., Wang, Y., Liu, H., Wu, S. \& Li, C. (2015). Using Particle Swarm Optimization Approach for Student Engagement Measurement. International Journal of Learning, Teaching and Educational Research Vol. 11, No. 1, pp. 12-21.

[44] Bassani, S. P. B. (2011). Interpersonal exchanges in discussion forums: A study of learning communities in distance learning settings. Computers \& Education, 56(4), 931-938.

[45] Hämäläinen, R., \& Häkkinen, P. (2010). Teachers' instructional planning for computer-supported collaborative learning: Macro-scripts as a pedagogical method to facilitate collaborative learning. Teaching and Teacher Education, 26(4), 871-877.

[46] Woolley, A. W., Chabris, C. F., Pentland, A., Hashmi, N. \& Malone, T. W. (2010). Evidence for a collective intelligence factor in the performance of human groups.Science, 330, 686-688.

[47] Sidnell, J. (2010). Conversation Analysis. AN INTRODUCTION. Wiley-Blackwell

[48] Gikandi, J. W., Morrow, D. \& Davis, N. E. (2011). Online formative assessment in higher education: A review of the literature. Computers \& Education, 57(4), 2333-2351.

[49] Lee, R., \& Dashew, B. (2011). Designed learner interactions in blended course delivery. Journal of Asynchronous Learning Networks, 15(1), 72-80.

[50] Abawajy, J. (2012). Analysis of Asynchronous Online Discussion Forums for Collaborative Learning. International Journal of Education and Learning Vol. 1, No. 2, September, 2012. pp. 11-22.

[51] Flórez, M. T. \& Sammons, P. (2013). Assessment for learning: effects and impact. Copyright CfBT Education Trust 2013.

[52] Ültanır, E. (2012). An Epistemological Glance at the Constructivist Approach: Constructivist Learning in Dewey, Piaget and Montessori. International Journal of Instruction. 5 (2), 195-212.

[53] Dingel, M. J., Wei, W. \& Huq, A. (2013). Cooperative learning and peer evaluation: The effect of free riders on team performance and the relationship between course 
performance and peer evaluation. Journal of the Scholarship of Teaching and Learning, Vol. 13, No. 1, 45 $-56$.

[54] Hall, P., \& Weaver, L. (2001). Interdisciplinary education and teamwork: a long and winding road. Medical Education, 35(9), 867-875.

[55] Dreyfus, A., Jungwirth, E., and Eliovitch, R. (1990). Applying the cognitive conflict strategy for conceptual change: Some implications, difficulties, and problems. Science Education, 74(5), 555-569.

[56] Strijbos, J. W. \& De Laat, M. F. (2010). Developing the role concept for computer-supported collaborative learning: An explorative synthesis. Computers in Human Behavior, 26(4), 495-505.

[57] Deiglmayr, A. \& Rummel, N. (2015). The Mediating Role of Interactive Learning Activities in CSCL: An INPUTPROCESS-OUTCOME Model.

[58] Chiu, M.M. (2000). Group Problem-Solving Processes: Social Interactions and Individual Actions. Journal for the Theory of Social Behaviour 30:1. Pp 27-49.

[59] Sarmiento, J. W. \& Shumar, W. (2010). Boundaries and roles: Positioning and social location in the Virtual Math Teams (VMT) online community. Computers in Human Behavior, 26(4), 524-532.

[60] Hou, H.-T. (2012). Analyzing the Learning Process of an Online Role-Playing Discussion Activity. Educational Technology \& Society, 15 (1), 211-222.

[61] Stahl, G. (2011b). Knowledge Negotiation in in Asynchronous Learning Networks.

[62] Puntambekar, S., \& Young, M. F. (2003). Moving toward a theory of CSCL. In U. Hoppe, B. Wasson, \& S. Ludvigson (Eds.), Computer supported collaborative learning 2003: Designing for change in networked learning (pp. 503-512). Amsterdam: IOS Press.

[63] Hamdan, N. A. \& Schaper, H. (2012). Collaboration in Mobile Learning Seminar: Mobile Learning 2011/2012. Computer-Supported Learning Research Group.

[64] Erlin, Norazah, Y. \& Azizah, A. R. (2008). Overview on agent application to support collaborative learning interaction. Jan. 2008, Volume 5, No.1 (Serial No.38) USChina Education Review,ISSN 1548-6613,USA.

[65] Glassmeyer, D. M., Dibbs, R. A. \& Jensen, R. T. (2011). Determining utility of formative assessment through virtual community: Perspectives of online graduate students. Quarterly Review of Distance Education, 12(1), 23-35.

[66] Oboko, R. O. (2012). Adaptive Learning and Metacognitive Regulation Support for Ill-Structured Problem Solving Processes (Unpublished PhD Thesis). University of Nairobi, Kenya.

[67] Van der Meijden, H. (2005). Knowledge Construction through CSCL: Student Elaborations in synchronous, asynchronous, and three-dimensional learning environments. (Unpublished Doctoral Thesis). Radboud University, Nijmegen, Netherlands.

[68] Landis, J.R. \& Koch, G.G. (1977). The measurement of observer agreement for categorical data. Biometrics. 33(1), 159-174.

\section{Authors' Profiles}

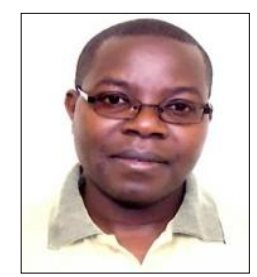

Stephen T. Njenga is currently pursuing a Phd. in Computer Science in the University of Nairobi, Kenya. Njenga received Msc. in Computer Science from the University of Nairobi, Kenya in 2011 and a Bsc. in Computer Science from Egerton University, Kenya in 1998.

$\mathrm{He}$ is currently a Lecturer in the School of Computing and Information Technology in Murang'a University of Technology. He has taught in the field of Computer Science in universities and tertiary colleges for more than eighteen years. His research interest is in the field of Artificial Intelligence, Mobile Learning and Intelligent Mobile Applications.

Mr. Njenga is a member of the Institute of Electronic and Electrical Engineer (IEEE).

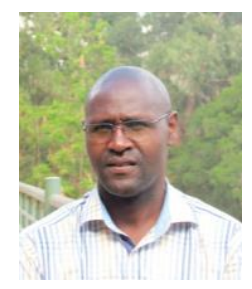

Robert O. Oboko received his Msc. Computer science from Free University of Brussels and $\mathrm{PhD}$ in Computer Science from University of Nairobi.

$\mathrm{He}$ is a Lecturer in the School of Computing and Informatics in the University of Nairobi, Kenya. His research interests are mainly in issues around the use of ICT for Development. These include issues around application of ICT in Education, Monitoring and Evaluation, health, enhancement of Social Capital, and ICT4D policy research, among others. He is also keen on the use of machine learning and mobile devices for development.

Dr. Oboko regularly publishes international refereed journal papers, refereed international conferences papers and book chapters.

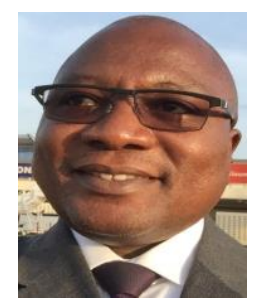

Elijah I. Omwenga holds a $\mathrm{PhD}$ in Computer Science from the University of Nairobi in the area of Information Systems. $\mathrm{He}$ is engaged in research on deployment of low bandwidth mobile applications as well as integration of ICT in learning institutions.

Prof. Omwenga is the President of the African Association for Teacher Educators and the African representative to the World Forum for Associations of Teacher Educators (WFATE). He is not only a seasoned Software Engineer but also an author of over thirty (30) scientific papers in reputable journals and publications, tens of technical papers, and an author of three books.

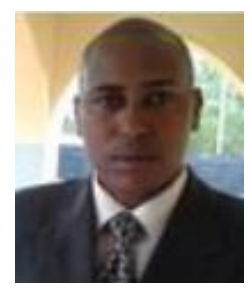

Elizaphan M. Maina received B.ED Science degree from Kenyatta University, Kenya in 2000, Postgraduate Diploma in Computer Science from University of Nairobi, Kenya in 2002, Msc. in Information Systems from University of Nairobi, Kenya in 2005 and $\mathrm{PhD}$ in Computer Science from University of Nairobi, Kenya in 2015. 
$\mathrm{He}$ is a Lecturer in the Department of Computing and Information Technology at Kenyatta University, Kenya. He has taught computer Science for ten years in Universities and Tertiary colleges. His primary research focus is on integration of artificial intelligence techniques in e-learning in order to create new e-learning pedagogies which can support personalized e-learning and also provide computer supported collaborative learning. His current research examines improving of online collaborative learning using machine learning techniques.

Dr. Maina has published journals in the field of artificial intelligence and e-learning. He lecturers in the field of artificial intelligence, programming, database systems and use of ICT in Education.

How to cite this paper: Stephen T. Njenga, Robert O. Oboko, Elijah I. Omwenga, Elizaphan M. Maina, "Use of Intelligent Agents in Collaborative M-Learning: Case of Facilitating Group Learner Interactions", International Journal of Modern Education and Computer Science(IJMECS), Vol.9, No.10, pp. 18-28, 2017.DOI: 10.5815/ijmecs.2017.10.03 